BBA 41126

\title{
THE INTERACTION BETWEEN BICARBONATE AND THE HERBICIDE IOXYNIL IN THE THYLAKOID MEMBRANE AND THE EFFECTS OF AMINO ACID MODIFICATION ON BICARBONATE ACTION
}

\author{
WIM F.J. VERMAAS ${ }^{a}$, JACK J.S. VAN RENSEN ${ }^{b}$ and GOVINDJEE ${ }^{a, *}$ \\ ${ }^{a}$ Departments of Physiology and Biophysics, and Botany, University of Illinois, 289 Morrill Hall, 505 S. Goodwin Avenue, Urbana, IL \\ 61801 (U.S.A.) and ${ }^{b}$ Laboratory of Plant Physiological Research, Agricultural University, Gen Foulkesweg 72, 6703 BW Wageningen \\ (The Netherlands)
}

(Received December 21st, 1981)

Key words: Photosystem II; Herbicide; Bicarbonate effect; Protein modification; Thylakoid membrane; (Pea chloroplast)

Bicarbonate depletion of chloroplast thylakoids reduces the affinity of the herbicide, ioxynil, to its binding site in Photosystem (PS) II. This herbicide is found to be a relatively more efficient inhibitor of the Hill reaction when $\mathrm{HCO}_{3}^{-}$is added to $\mathrm{CO}_{2}$-depleted thylakoids in subsaturating rather than in saturating concentrations. The reason for this dependence of the inhibitor efficiency on the $\mathrm{HCO}_{3}^{-}$concentration is that the inactive $\mathrm{HCO}_{3}^{-}$-deficient PS II reaction chains bind less ioxynil than the active PS II electron-transport chains that have bound $\mathrm{HCO}_{3}^{-}$, and, thus, after addition of a certain amount of ioxynil the concentration of the free herbicide increases when the $\mathrm{HCO}_{3}^{-}$concentration decreases. Therefore, the inhibition of electron transport by ioxynil increases at decreasing $\mathrm{HCO}_{3}^{-}$levels. Measurements on the effects of modification of lysine and arginine residues on the rate of electron transport are also presented: the rate of modification is faster in the presence than in the absence of $\mathrm{HCO}_{3}^{-}$. Therefore, we suggest that surface-exposed lysine or arginine residues are not involved in binding of $\mathrm{HCO}_{3}^{-}$(or $\mathrm{CO}_{2}$ or $\mathrm{CO}_{3}^{2-}$ ) to its binding protein, but that $\mathrm{HCO}_{3}^{-}$influences the conformation of its binding environment such that the affinity for certain herbicides and the accessibility for amino acid modifiers are changed.

\section{Introduction}

The presence of $\mathrm{HCO}_{3}^{-}$(or $\mathrm{CO}_{2}$ or $\mathrm{CO}_{3}^{2-}$ ) is indispensible for efficient photosynthetic electron transport in chloroplast thylakoids [1-3]. Since it is not yet certain whether $\mathrm{HCO}_{3}^{-}, \mathrm{CO}_{2}$ or $\mathrm{CO}_{3}^{2-}$ (or a combination of these) is (are) responsible for this 'bicarbonate effect', we use ' $\mathrm{HCO}_{3}^{-}{ }^{*}$ ' to indicate the species that binds to the thylakoid mem-

\footnotetext{
* To whom reprint requests should be sent. Abbreviations: PS, photosystem; Chl, chlorophyll; DCIP, 2,6dichlorophenolindophenol; diuron, 3-(3,4-dichlorophenyl)-1,1dimethylurea (DCMU); atrazine, 2-chloro-4-ethylamino-6-isopropylamino-s-triazine; dinoseb, 2,4-dinitro-6-(1-methylpropyl)phenol; ioxynil, 4-hydroxy-3,5-diiodobenzonitrile; simeton, 2-methoxy-4,6-bisethylamino-1,3,5-triazine.
}

brane and that is necessary for electron transport. It has been shown by a number of different techniques (electron transport, $\mathrm{Chl} a$ fluorescence, and absorption change measurements) that the most important site of $\mathrm{HCO}_{3}^{-*}$ action is between the first PS II electron-accepting quinone $\mathrm{Q}$ and $\mathrm{PQ}$ (plastoquinone) [4-12]. The strong influence of $\mathrm{HCO}_{3}^{-*}$ on electron transport at the quinone level might imply that $\mathrm{HCO}_{3}^{-*}$ interacts with the 32-34 $\mathrm{kDa} \mathrm{B}$-apoprotein, which is known to bind herbicides like atrazine and diuron [13-15], or with a 41-47 kDa protein suggested to bind phenolic herbicides [16,17]. Competition studies between $\mathrm{HCO}_{3}^{-*}$ and herbicides, carried out by Van Rensen and Vermaas [6], showed that diuron, simeton (a triazine) and 4,6-dinitro-o-cresol (a phenolic 
herbicide) are relatively more potent inhibitors when a smaller number of the $\mathrm{HCO}_{3}^{-*}$-binding sites are occupied by $\mathrm{HCO}_{3}^{-*}$. A Lineweaver-Burk plot indicated full competition between $\mathrm{HCO}_{3}^{-}$* and 4,6-dinitro- $o$-cresol, and a partial competition between $\mathrm{HCO}_{3}^{-*}$ and diuron or simeton. However, Khanna et al. [7] reported a decrease in the affinity of $\left[{ }^{14} \mathrm{C}\right]$ atrazine for its binding site in the absence of $\mathrm{HCO}_{3}^{-*}$; this result is apparently opposite to what may be expected in the case of a competition between $\mathrm{HCO}_{3}^{-*}$ and herbicides. In this paper, we present data on interactions between $\mathrm{HCO}_{3}^{-*}$ and the herbicide ioxynil, and provide an explanation for the above-mentioned apparent disagreement between competition and binding studies.

Renger and co-workers [18] reported the effects of glutaraldehyde on the acceptor side of PS II: a modification of (probably) lysine residues by glutaraldehyde treatment led to a decrease in the reduction of $Q$, but not to a significant decrease in the rate of electron transport from $Q$ to $P Q$. We extended the protein modification experiments to investigate if lysine or arginine residues may be involved in the bicarbonate effect.

\section{Materials and Method}

Chloroplast isolation and Hill reaction measurements. Chloroplasts were isolated from 10-15-dayold pea ( Pisum sativum L.) leaves and were broken as described earlier [19]. $\mathrm{CO}_{2}$ depletion was performed by washing the thylakoids once in a formate-containing buffer $(50 \mathrm{mM}$ sodium phosphate, $100 \mathrm{mM} \mathrm{NaCl}, 100 \mathrm{mM} \mathrm{HCO} \mathrm{Ha}_{2}, 5 \mathrm{mM}$ $\mathrm{MgCl}_{2}$ ), $\mathrm{pH} 5.3$, or by shaking the thylakoids suspended in this buffer for $10 \mathrm{~min}$ while $\mathrm{CO}_{2}$-free $\mathrm{N}_{2}$ was led over the suspension ([Chl] $=30-50$ $\mu \mathrm{g} / \mathrm{ml})$. The $\mathrm{CO}_{2}$-depleted thylakoids were resuspended in a buffer of the same composition at $\mathrm{pH}$ 6.5. The buffers and tubes were kept $\mathrm{CO}_{2}$ free. For a more detailed description of the $\mathrm{CO}_{2}$-depletion procedure, see Refs. 11 and 20.

The ferricyanide Hill reaction was measured as oxygen evolution using a Clark-type electrode. The DCIP Hill reaction was monitored at $595 \mathrm{~nm}$ as DCIP reduction using a Cary 14 spectrophotometer. The difference in the extinction coefficient between oxidized and reduced DCIP at $595 \mathrm{~nm}$ was taken to be $18 \mathrm{mM}^{-1} \cdot \mathrm{cm}^{-1}$ at $\mathrm{pH} 7.0$ [21]. The actinic light was filtered through a Corning 2-67 red filter, and the photomultiplier of the spectrophotometer was shielded by a $595 \mathrm{~nm}$ interference filter.

Chl a fluorescence measurements. The instrument used to measure fluorescence induction kinetics in dark-adapted chloroplasts has been described elsewhere [11]. Excitation light, obtained from a tungsten lamp, was passed through a narrow-band $660 \mathrm{~nm}$ interference filter before it impinged on the sample. Chl $a$ fluorescence, after having passed a monochromator (set at $690 \mathrm{~nm}$, with a half-bandwidth of $5 \mathrm{~nm}$ ), was detected by an S-20 photomultiplier.

Ioxynil binding. $\left[{ }^{14} \mathrm{C}\right]$ Ioxynil (spec. act. 33.5 $\mu \mathrm{Ci} / \mathrm{mg}$ ) was added to $1 \mathrm{ml}$ of a suspension $(80 \mu \mathrm{g}$ Chl) of $\mathrm{CO}_{2}$-depleted thylakoids with or without the addition of $10 \mathrm{mM} \mathrm{NaHCO}$. The suspension was incubated for $15 \mathrm{~min}$ at room temperature in the dark, and then the thylakoids were pelleted by centrifugation; $0.8 \mathrm{ml}$ of the supernatant was transferred to a scintillation vial with $10 \mathrm{ml}$ scintillation fluid. The amount of free $\left[{ }^{14} \mathrm{C}\right]$ ioxynil was measured and the amount bound to the thylakoid membrane was then calculated.

Protein modification. Thylakoids were $\mathrm{CO}_{2}$ depleted and resuspended into $50 \mathrm{mM}$ sodium phosphate, $20 \mathrm{mM} \mathrm{HCO}_{2} \mathrm{Na}, 10 \mathrm{mM} \mathrm{NaCl}, 5 \mathrm{mM}$ $\mathrm{MgCl}_{2}$ and $0.2 \mathrm{M}$ mannitol (final $\mathrm{pH}=7.0$ ). Then, $10 \mathrm{mM} \mathrm{NaHCO}$ and $2 \mathrm{mM} \mathrm{HCl}$ (to keep the $\mathrm{pH}$ at 7.0) were added to half of the samples. Subsequently, $50 \mathrm{mM}$ phenylglyoxal (to modify arginine residues [22]) or $5 \mathrm{mM}$ pyridoxal 5-phosphate (to modify lysine residues [23]) was added. After incubation with the modifier for the time indicated at room temperature in the dark, the suspension was centrifuged $(5 \mathrm{~min} ; 1000 \times \mathrm{g})$ and the thylakoid pellet was resuspended into a buffer containing $50 \mathrm{mM}$ sodium phosphate, $10 \mathrm{mM}$ $\mathrm{NaHCO}_{3}, 10 \mathrm{mM} \mathrm{NaCl}, 5 \mathrm{mM} \mathrm{MgCl}, 0.2 \mathrm{M}$ mannitol (final $\mathrm{pH} 7.0)([\mathrm{Chl}]=33 \mu \mathrm{g} / \mathrm{ml})$. Then, $50 \mu \mathrm{M}$ DCIP was added and the Hill reaction was measured. The modification was also monitored by $\mathrm{Chl} a$ fluorescence measurements. Control experiments, in which no amino acid modifier was added, were also performed. 


\section{Results and Discussion}

\section{Ioxynil binding}

For ioxynil, the $I_{50}$ value (i.e., the herbicide concentration at which $50 \%$ inhibition of electron transport is observed) and the binding constant are comparable [17]; this indicates that there is little ioxynil binding to the groups in the thylakoid membrane that are not directly involved in photosynthesis at ioxynil concentrations lower than $I_{50}$. Thus, binding experiments using ioxynil concentrations lower than $I_{50}$ can be reliably used to measure the ioxynil affinity for the site influencing electron transport. A double-reciprocal plot of the concentrations of ioxynil that is free and that is bound to the thylakoids with or without $\mathrm{HCO}_{3}^{-}$ addition is shown in Fig. 1. This plot indicates that the number of binding sites ( 1 per $480 \mathrm{Chl}$ molecules) is not significantly changed by $\mathrm{HCO}_{3}^{-}$addition to $\mathrm{CO}_{2}$-depleted thylakoids. The binding constant, $K_{\mathrm{b}}$, however, is approx. $10 \mathrm{nM}$ in the presence and approx. $30 \mathrm{nM}$ in the absence of $\mathrm{HCO}_{3}^{-}$. This means that the presence of $\mathrm{HCO}_{3}^{-}$leads to an increased affinity of $\left[{ }^{14} \mathrm{C}\right]$ ioxynil to the binding site, and, thus, these data would not suggest any competition between $\mathrm{HCO}_{3}^{-*}$ and ioxynil. (Atrazine affinity has been shown to depend on $\mathrm{CO}_{2}$ depletion in qualitatively the same way as that of ioxynil [7].). However, our measurements on the sensitivity of the ferricyanide Hill reaction to

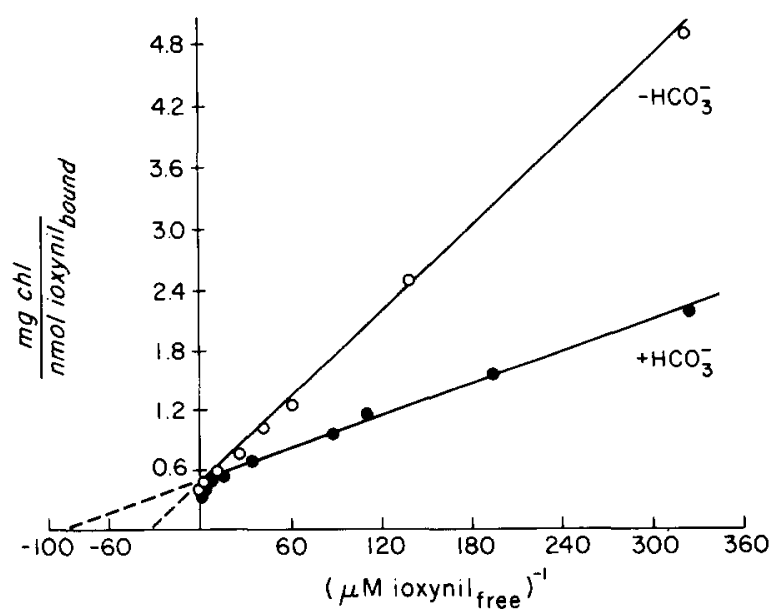

Fig. 1. Double-reciprocal plot of free and bound $\left[{ }^{14} \mathrm{C}\right]$ ioxynil to $\mathrm{CO}_{2}$-depleted thylakoids with $(\bullet)$ and without $(\mathrm{O})$ addition of $10 \mathrm{mM} \mathrm{NaHCO} 3$ prior to ioxynil addition (20-700 nM ioxynil). ioxynil in $\mathrm{CO}_{2}$-depleted thylakoids after addition of various concentrations of $\mathrm{HCO}_{3}^{-}$suggest a (partial) competition between $\mathrm{HCO}_{3}^{-*}$ and ioxynil (Fig. 2): the thylakoids are more sensitive to ioxynil at lower than at higher $\mathrm{HCO}_{3}^{-*}$ concentration. Similar results have been reported for $\mathrm{HCO}_{3}^{-*}$. diuron and $\mathrm{HCO}_{3}^{-*}$-simeton interactions [6]. At first glance, the results shown in Figs. 1 and 2 seem to be contradictory. However, other experiments [7,11] suggest that electron-transport chains, in which no $\mathrm{HCO}_{3}^{-*}$ is bound to a site in the vicinity of or at the $32-34 \mathrm{kDa}$ herbicide-binding protein, are fully inactive; thus, electron transport in $\mathrm{CO}_{2}$-depleted chloroplasts is only due to chains in which an $\mathrm{HCO}_{3}^{-*}$ molecule is bound near the quinones $\mathrm{Q}$ and $\mathrm{B}$. Since the binding constant of ioxynil for its site is lower when no $\mathrm{HCO}_{3}^{-*}$ is bound near that site, the concentration of free ioxynil is higher at low concentrations of $\mathrm{HCO}_{3}^{-}$ than at higher $\mathrm{HCO}_{3}^{-}$levels (less ioxynil is bound to the site), resulting in a greater inhibition of the still active electron-transport chains at low than at high $\mathrm{HCO}_{3}^{-}$concentrations. Indeed, the observed $\mathrm{HCO}_{3}^{-}$dependence of inhibition by $100 \mathrm{nM}$ ioxynil (approx. 35\% at saturating $\mathrm{HCO}_{3}^{-}$levels, approx. $62 \%$ in the presence of $0.5 \mathrm{mM} \mathrm{NaHCO}$; see Fig. 2) can be easily explained by a 3 -fold change

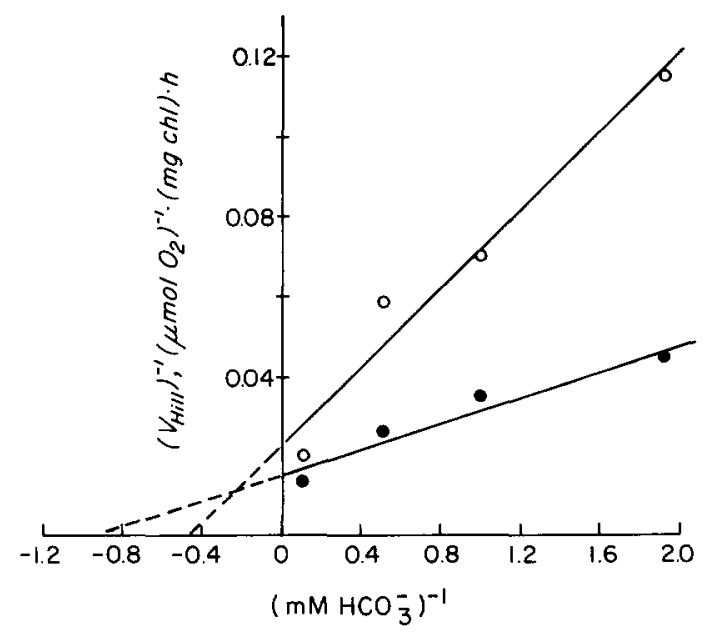

Fig. 2. Double-reciprocal plot of the ferricyanide Hill reaction rate $\left(v_{\mathrm{Hill}}\right)$ as a function of the $\mathrm{HCO}_{3}^{-}$concentration in the absence (O) and presence $(O)$ of $100 \mathrm{nM}$ ioxynil. The thylakoids were allowed to incubate with $\mathrm{HCO}_{3}^{-}$for $2 \mathrm{~min}$. The time between ioxynil addition and the measurement of its effect was $3.5 \mathrm{~min}$. The ferricyanide concentration was $0.5 \mathrm{mM}$. 
in ioxynil affinity. Therefore, the observed increased sensitivity for ioxynil of the ferricyanide Hill reaction in $\mathrm{CO}_{2}$-depleted thylakoids resupplied with subsaturating amounts of $\mathrm{HCO}_{3}^{-}$is probably due to a higher ioxynil concentration in solution.

This explanation meets with problems in the case of 4,6-dinitro- $o$-cresol, which was suggested, based on studies of the inhibition of the Hill reaction by 4,6-dinitro-o-cresol at various $\mathrm{HCO}_{3}^{-}$ levels, to interact with $\mathrm{HCO}_{3}^{-*}$ competitively: the $I_{50}$ value for 4,6-dinitro-o-cresol is relatively high (approx. $10^{-5} \mathrm{M}$ ), and, thus, in the presence of a concentration of 4,6-dinitro-o-cresol that inhibits electron transport by $30-50 \%$, the amount of $4,6-$ dinitro-o-cresol released from binding sites $(10-100$ $\mathrm{nM})$ due to a lower affinity when no $\mathrm{HCO}_{3}^{-} *$ is bound in the vicinity is negligible compared to the free 4,6-dinitro-o-cresol concentration already present. Therefore, when the only interaction between $\mathrm{HCO}_{3}^{-*}$ and 4,6-dinitro-o-cresol would be one comparable to that between $\mathrm{HCO}_{3}^{-*}$ and ioxynil, then the inhibition by 4,6-dinitro-o-cresol would be expected to be independent of the $\mathrm{HCO}_{3}^{-}$* level. We suggest that the interaction between $\mathrm{HCO}_{3}^{-*}$ and herbicides containing a phenol group (such as ioxynil and 2,4-dinitro-o-cresol) may be strongly dependent on the structure of the phenolic herbicide: the ioxynil affinity is decreased in the absence of $\mathrm{HCO}_{3}^{-*}$, whereas such behavior does not seem to explain the results obtained with 4,6-dinitro-o-cresol [6], or with the slightly more powerful phenolic herbicides i-dinoseb and dinoseb (Van Rensen, J.J.S., unpublished results). This might indicate that the side groups of the phenol-group containing herbicides are very important in determining the mode of interaction (cf. Ref. 24). This would point to very closely related, but not identical, binding sites for $\mathrm{HCO}_{3}^{-*}$ and herbicides.

\section{Protein modification}

As mentioned in the Introduction, the influence of modification of amino acids of thylakoids proteins on photosynthetic electron transport is still largely unknown. However, such modifications may provide information on the groups of a protein involved in an electron-transport process, and, furthermore, may provide insight into the mecha- nism of $\mathrm{HCO}_{3}^{-*}$ action. Therefore, we investigated the effect of lysine and arginine modification on the bicarbonate effect. The results of lysine modification experiments are shown in Table I. These data indicate that modification of certain lysine residues in proteins influencing electron transport occurs at a somewhat higher rate in the presence than in the absence of $\mathrm{HCO}_{3}^{-*}$. If this was due to a modification of some amino acid residues at the $\mathrm{HCO}_{3}^{-}$-binding site, then the opposite result would have been expected: in the absence of $\mathrm{HCO}_{3}^{-*}$ (the binding site not occupied by $\mathrm{HCO}_{3}^{-*}$ ) a faster modification of the $\mathrm{HCO}_{3}^{-*}$-binding site would occur than in its presence. In control experiments (without protein modifier) the DCIP Hill reaction rate was decreased by only approx. $35 \%$ after a $2 \mathrm{~h}$ incubation. Fig. 3 shows that the variable Chl $a$ fluorescence $\left(F_{\mathrm{v}}\right)$ almost disappears after lysine modification and that the long-term (greater than $10 \mathrm{~s}$ after illumination) fluorescence yield $\left(F_{\max }\right)$ is lowered. Modification in the absence of $\mathrm{HCO}_{3}^{-*}$ leads to qualitatively identical fluoresence induction curves. It is interesting to note that the initial fluoresence yield $\left(F_{0}\right)$ after modification is higher than before modification. Incubation with 1 or $10 \mathrm{mM} \mathrm{NH} \mathrm{N}_{2} \mathrm{OH}$ (which donates electrons, presumably indirectly, to P-680)

TABLE I

EFFECT OF LYSINE RESIDUE MODIFICATION IN THE PRESENCE AND THE ABSENCE OF $\mathrm{HCO}_{3}^{-*}$ ON THE DCIP HILL REACTION

All thylakoids used in this experiment were previously $\mathrm{CO}_{2}$ depleted; to all samples, except those used for measuring the control activity, $5 \mathrm{mM}$ pyridoxal 5-phosphate was added when the incubation was started; furthermore, $10 \mathrm{mM} \mathrm{NaHCO}_{3}+$ $2 \mathrm{mM} \mathrm{HCl}$ was added to the " $+\mathrm{HCO}_{3}^{-}$' samples at the beginning of the incubation. The DCIP Hill reaction was measured in the presence of $10 \mathrm{mM} \mathrm{NaHCO}$ after washing out the modifier. $100 \%$ activity conesponds to $130 \mu \mathrm{mol}$ DCIP reduced/mg Chl per h.

\begin{tabular}{|c|c|c|c|}
\hline \multirow{2}{*}{$\begin{array}{l}\text { Incubation } \\
\text { time } \\
(\min )\end{array}$} & \multicolumn{2}{|c|}{ Activity $(\%)(n=4)$} & \multirow{2}{*}{$\begin{array}{l}\text { Control } \\
\text { activity }(\mathscr{E}) \\
\left(+ \text { or }-\mathrm{HCO}_{3}^{-}\right)\end{array}$} \\
\hline & $-\mathrm{HCO}_{3}^{-}$ & $+\mathrm{HCO}_{3}^{-}$ & \\
\hline 0 & 100 & 100 & 100 \\
\hline 10 & $95 \pm 5$ & $93 \pm 8$ & 98 \\
\hline 30 & $75 \pm 7$ & $62 \pm 6$ & 89 \\
\hline 60 & $58 \pm 5$ & $32 \pm 4$ & 80 \\
\hline 120 & $24 \pm 3$ & $14 \pm 3$ & 64 \\
\hline
\end{tabular}




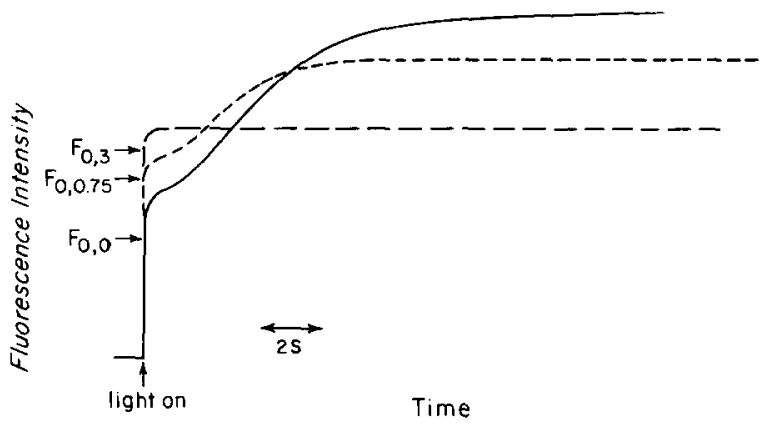

Fig. 3. Chl a fluorescence induction curves of $\mathrm{CO}_{2}$-depleted thylakoids after $0(-\ldots), 0.75(-\ldots)$ and $3(---) \mathrm{h}$ of incubation with $5 \mathrm{mM}$ pyridoxal 5-phosphate. The initial level $\left(F_{0}\right)$ in all the three cases is indicated. At the beginning of the incubation, $10 \mathrm{mM} \mathrm{NaHCO}$ and $2 \mathrm{mM} \mathrm{HCl}$ were added. After incubation for the indicated time, the thylakoids were pelleted and resuspended into pyridoxal 5-phosphate-free medium; $[\mathrm{Chl}]=10 \mu \mathrm{g} / \mathrm{ml}$.

for $10 \mathrm{~min}$ does not change the fluorescence induction curves significantly (data not shown), indicating that the observed modification effects are not located on the donor side of PS II. Using control chloroplasts (without modifier), neither the ratio of $F_{\max }$ to $F_{0}$ nor $F_{\max }$ changes very significantly during a $3 \mathrm{~h}$ incubation at room temperature: both the $F_{\max } / F_{0}$ ratio and $F_{\max }$ decreased by only approx. $25 \%$. These results might indicate that the lysine modification changes the conformation of the vicinity of the PS II reaction center and antenna (resulting in an increase in the $F_{0}$ yield), and influences stacking properties of the thylakoids, or charge separation between P-680 and Q, or both (resulting in a loss of $F_{\mathrm{v}}$ ). We note that the lysine modification results reported here somewhat resemble the results of glutaraldehyde treatment of thylakoid membranes as presented by Renger and co-workers [18]. This is not surprising because glutaraldehyde is supposed to react with lysine residues [25].

In order to investigate if arginine might play a role in $\mathrm{HCO}_{3}^{-*}$ binding, we performed experiments with the arginine modifier phenylglyoxal. Modification by $50 \mathrm{mM}$ phenylglyoxal gives results qualitatively similar to those with lysine modification: the modification rate (as measured by a decrease in the DCIP Hill reaction) is higher in the presence of $\mathrm{HCO}_{3}^{-*}$ than in its absence, and the variable fluorescence disappears after $2 \mathrm{~h}$ of mod- ification. Hydroxylamine treatment does not appear to change the fluorescence characteristics, again suggesting an effect on the acceptor rather than on the donor side of PS II.

The absence of a positive correlation between the absence of $\mathrm{HCO}_{3}^{-*}$ and lysine or arginine modification indicates that the $\mathrm{HCO}_{3}^{-*}$-binding site (1) is inaccessible to the modifier (thus, not surface exposed, which is in agreement with the idea that the $\mathrm{HCO}_{3}^{-}$-binding site is hidden under the membrane surface [20]); or (2) does not contain a lysine or arginine that is uncharged at the $\mathrm{pH}$ used. The latter possibility would imply that the mechanism of $\mathrm{HCO}_{3}^{-*}$ action on photosynthetic electron transport is not the formation of a carbamate ( $\mathrm{R}-\mathrm{NH}-\mathrm{CO}_{2}^{-}$) from $\mathrm{CO}_{2}$ and a free amino group. Consistent with this possibility is the preliminary observation that diazomethane (that stabilizes carbamates) does not change the $\mathrm{H}^{14} \mathrm{CO}_{3}^{-}$binding characteristics to $\mathrm{CO}_{2}$-depleted chloroplasts (Govindjee and co-workers, unpublished results). However, carbamate formation has been shown to be involved in the stimulation of ribulose-1,5-bisphosphate carboxylase/oxygenase by $\mathrm{CO}_{2}[26]$.

We consider it very likely that $\mathrm{HCO}_{3}^{-*}$ binding changes the conformation of a protein, presumably located on the outer side of the thylakoid membrane, in such a way that lysine and arginine residues become somewhat better accessible to amino acid modifiers. Our data, both on herbicide binding (Figs. 1 and 2) and protein modification (Table 1; Fig. 3) point to a direct influence of $\mathrm{HCO}_{3}^{-*}$ on the conformation of the herbicidebinding protein(s) and, possibly, of other proteins in the vicinity. This effect of $\mathrm{HCO}_{3}^{-*}$ on protein conformation is presumably responsible for the large modification of electron transport at the quinone level by $\mathrm{HCO}_{3}^{-*}$.

\section{Acknowledgements}

The $\left[{ }^{14}\right.$ Clioxynil-binding studies were performed in the laboratory of Dr. Charles J. Arntzen (MSU-DOE Plant Research Laboratory, East Lansing, MI 48824, U.S.A.). We are thankful to him for his hospitality and for fruitful discussions. $\left[{ }^{14} \mathrm{C}\right]$ Ioxynil was a generous gift from May \& Baker, U.K. This research was supported by an NSF grant (78-24532) to G. 


\section{References}

1 Warburg, O. and Krippahl, G. (1958) Z. Naturforsch. 13b, 509-514

2 Govindjee and Van Rensen, J.J.S. (1978) Biochim. Biophys. Acta 505, 183-213

3 Vermaas, W.F.J. and Govindjee (1981) Proc. Indian Natl. Sci. Acad. B47, 581-605

4 Khanna, R., Wydrzynski, T. and Govindjee (1977) Biochim. Biophys. Acta 462, 208-214

5 Van Rensen, J.J.S. and Vermaas, W.F.J. (1981) in Proceedings of the 5th International Congress on Photosynthesis (Akoyunoglou, G., ed.), Vol. 2, pp. 151-156, Balaban International Science Service, Philadelphia.

6 Van Rensen, J.J.S. and Vermaas, W.F.J. (1981) Physiol. Plant. 51, 106-110

7 Khanna, R., Pfister, K., Keresztes, A., Van Rensen, J.J.S. and Govindjee (1981) Biochim. Biophys. Acta 634, 105-116

8 Wydrzynski, T. and Govindjee (1975) Biochim. Biophys. Acta 387, 403-408

9 Govindjee, Pulles, M.P.J., Govindjee, R., Van Gorkom, H.J. and Duysens, L.N.M. (1976) Biochim. Biophys. Acta 449, 602-605

10 Jursinic, P., Warden, J. and Govindjee (1976) Biochim. Biophys. Acta 440, 322-330

11 Vermaas, W.F.J. and Govindjee (1982) Biochim. Biophys. Acta 680, 202-209

12 Siggel, U., Khanna, R., Renger, G. and Govindjee (1977) Biochim. Biophys. Acta 462, 196-207
13 Mattoo, A.K., Pick, U., Hoffman-Falk, H. and Edelman, M. (1981) Proc. Natl. Acad. Sci. U.S.A. 78, 1572-1576

14 Pfister, K., Steinback, K.E., Gardner, G. and Arntzen, C.J. (1981) Proc. Natl. Acad. Sci. U.S.A. 78, 981-985

15 Gardner, G. (1981) Science 211, 937-940

16 Oettmeier, W., Masson, K. and Johanningmeier, U. (1980) FEBS Lett. 118, 267-270

17 Oettmeier, W., Masson, K. and Johanningmeier, U. (1982) Biochim. Biophys. Acta 679, 376-383

18 Renger, G., Hagemann, R. and Dohnt, G. (1981) Biochim. Biophys. Acta 636, 17-26

19 Van Rensen, J.J.S., Wong, D. and Govindjee (1978) Z. Naturforsch. 33c, 413-420

20 Vermaas, W.F.J. and Van Rensen, J.J.S. (1981) Biochim. Biophys. Acta 636, 168-174

21 Armstrong, J. McD. (1964) Biochim. Biophys. Acta 86, 194-197

22 Takahashi, K. (1968) J. Biol. Chem. 243, 6171-6179

23 Markland, F.S., Bacharach, A.D.E., Weber, B.H., O'Grady, T.C., Saunders, G.C. and Umemura, N. (1975) J. Biol. Chem. 250, 1301-1310

24 Trebst, A., Reimer, S., Draber, W. and Knops, H.J. (1979) Z. Naturforsch. 34c, 831-840

25 Papageorgiou, G. (1979) in Photosynthesis in Relation to Model Systems (Barber, J., ed.), pp. 211-241, Elsevier/ North-Holland Amsterdam

26 Lorimer, G.H. and Miziorko, H.M. (1980) Biochemistry 19, 5321-5327 